This item was submitted to Loughborough's Research Repository by the author.

Items in Figshare are protected by copyright, with all rights reserved, unless otherwise indicated.

\title{
Developing air cargo operations at regional airports
}

PLEASE CITE THE PUBLISHED VERSION

http://dx.doi.org/10.1680/tran.13.00075

PUBLISHER

(C) ICE Publishing

VERSION

VoR (Version of Record)

LICENCE

CC BY-NC-ND 4.0

REPOSITORY RECORD

Budd, Lucy C.S., Stephen G. Ison, and Thomas Budd. 2019. "Developing Air Cargo Operations at Regional Airports". figshare. https://hdl.handle.net/2134/17452. 


\section{Developing air cargo operations at regional airports}

$1 \quad$ Lucy Budd BA, MSc, PhD

Senior Lecturer in Air Transport, Transport Studies Group, School of Civil and Building Engineering, Loughborough University, Loughborough, UK
2 Stephen Ison BA, MA, PhD, MCILT

Professor of Transport Policy, Transport Studies Group, School of Civil and Building Engineering, Loughborough University, Loughborough, UK

3 Thomas Budd BSc, PhD

Teaching and Research Fellow in Airport Planning and Management, Department of Air Transport, Cranfield University, Cranfield, UK
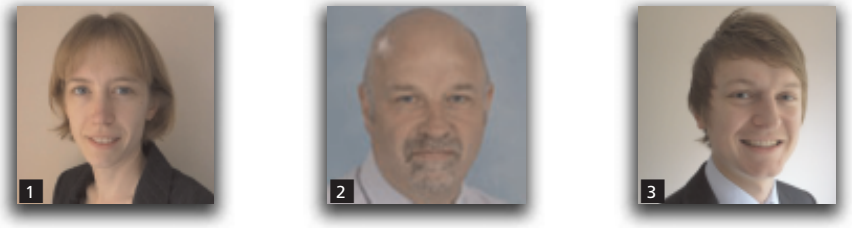

East Midlands airport (EMA) is a regional airport in northwest Leicestershire in central England. It is located roughly equidistant between the three Midlands' cities of Derby, Leicester and Nottingham and currently supports a range of full-service scheduled, charter and low-cost passenger operations to short- and medium-haul destinations in Europe as well as a significant number of long-haul intra and intercontinental freight services. In 2012, EMA was the thirteenth busiest passenger airport in the UK, handling just over four million customers a year, and the country's largest pure freight facility, processing almost $300000 \mathrm{t}$ of cargo and mail. By examining the historical development and commercial evolution of EMA from its opening as a commercial airport in 1965 to the present day, the paper details how a combination of far-sighted planning decisions and strategic management interventions have enabled EMA to diversify its operations and develop a unique operating niche that serves passenger flights during the day and cargo operations at night. The paper concludes by identifying elements of best practice and examining the extent to which the development of successful cargo operations at EMA could serve as a model for other regional airports worldwide that are seeking to develop complementary passenger and freight services.

\section{Introduction: The global significance of air cargo}

The ability to routinely transport large quantities of high valueto-weight time-critical consumer goods, industrial components and perishable commodities around the world by air is essential to the functioning of the modern world economy. In order to facilitate both the regular and the rapid just-in-time global mobility of over $48 \mathrm{Mt}$ of goods, worth some US\$ 5.3 trillion a year in 2010 (ATAG, 2012), the international air cargo sector requires the provision of specialist handling agents, dedicated warehouse facilities and integrated networks of intermodal logistics services in order to function quickly, safely, securely and efficiently across multiple time zones and different national regulatory regimes. As the interface between land and sky, airports play a vital role in the delivery of safe and efficient air cargo services worldwide, and many airport operators - particularly in times of economic downturn - are becoming increasingly attuned to the fact that cargo operations can help to augment the revenues that are derived from commercial passenger services. Local, regional and national economic agencies are also becoming aware of the direct economic impacts and myriad socio- economic 'trickle-down' effects of air cargo and many airports and regions worldwide are now promoting themselves as "cargo hubs' in an attempt to attract inward investment and stimulate economic growth. The fact that the twice-weekly Qatar Airways Boeing 777F flight from Doha to Atlanta alone generates around US\$ 12 million in annual economic benefits to the Atlanta metropolitan area (ACI-NA, 2012) illustrates the economic significance of air cargo connectivity.

Worldwide, over 172 billion revenue freight tonne kilometres were flown by commercial airlines in 2010 (ATAG, 2012) and it is estimated that $35 \%$ of all international trade by value (although only $0.5 \%$ by total volume) is transported by air. Air cargo underpins the international supply chains of many of the world's biggest biotech, pharmaceutical, aerospace, microelectronics, fashion and perishable food sectors (SDG, 2010), while diplomatic services and global sporting and entertainment brands such as Formula One racing heavily rely on the provision of air cargo services to support their operations. Kasarda et al. (2006), for example, estimate that $80 \%$ of the international trade in cut flowers and speciality meats and $60 \%$ of all fresh fish is 
Transport

Volume 168 Issue TR2
Developing air cargo operations at

regional airports

Budd, Ison and Budd transported by air, while electronics alone account for around $40 \%$ of the total value of air freight.

The global demand for air cargo and the diverse nature, weight, size and handling requirements of individual cargo consignments mean that the world's fleet of cargo aircraft contains a wide variety of aircraft types. These vary in size and range from small single-engine turboprops that fly small shipments into key distribution hubs to long-haul wide-bodied aircraft such as the B747-8F, the B777F and MD11F and specialist freighters such as the Antonov An-124 that can transport outsize loads. However, although air cargo flights operate on all seven continents, the spatial distribution of these services is highly uneven. The majority of cargo traffic is concentrated on key markets in (and between) destinations in North America, western Europe and east Asia and while significant air cargo markets are developing in central and southern Africa, air cargo remains a largely northern hemisphere phenomenon (Graham and Ison, 2014). Furthermore, as Bowen (2014) has shown, while the spatial structure of global air cargo services exhibits some similarity with passenger networks, cargo flows are more strongly localised around sites producing high value-to-weight goods (such as microelectronics and cool chain (i.e. products that have to be manufactured, transported and stored under strict temperature-controlled conditions) pharmaceutical products) and often operate into smaller and less congested regional airports that have the capacity and road transport infrastructure required to process large volumes of freight and night-time cargo flights.

While historically the world's major cargo airports developed close to large manufacturing centres and/or major metropolitan areas, others, such as Anchorage (Alaska), developed on account of being important transit and/or refuelling stops thanks to their strategic position at the intersections of major world trade routes. These original air freight centres have now been joined by a new generation of cargo airports that have been recently constructed to accommodate the specialist and often demanding requirements of the dynamic global logistics and cargo sector. As a consequence, the spatial distribution of cargo airports, both within and between countries and regions, exhibits some unique characteristics. Currently, the world's busiest cargo airports are located in east Asia, North America and the Middle East, reflecting both the historical and (in the case of Dubai) the growing economic importance of these regions (Table 1).

Although many of the major passenger airports also handle significant volumes of freight (Paris Charles de Gaulle, for example, is the busiest cargo airport in Europe, handling over $2 \cdot 1 \mathrm{Mt}$ of cargo in 2012, while London Heathrow is the biggest cargo airport in the UK (and the sixteenth biggest in the world) by volume, handling over $1.5 \mathrm{Mt}$ ), a number of specialist cargo facilities have also been developed at sites including Memphis, Frankfurt Hahn, Leipzig and Liege (Belgium). As Gardiner et al. (2005a, 2005b) have shown, these specialist cargo hubs are attractive to operators on account of their spare capacity, low(er)

\begin{tabular}{llcc}
\hline Airport & IATA code & $\begin{array}{c}\text { Cargo } \\
\text { handled: } t\end{array}$ & $\begin{array}{c}\text { Change year } \\
\text { on year: \% }\end{array}$ \\
\hline Hong Kong & HKG & 4161718 & $2 \cdot 3$ \\
Memphis & MEM & 4137801 & $3 \cdot 0$ \\
Shanghai & PVG & 2928527 & $-0 \cdot 3$ \\
Incheon & INC & 2464384 & $0 \cdot 3$ \\
Dubai & DXB & 2435567 & $6 \cdot 8$
\end{tabular}

Table 1. The world's top five cargo airports (by volume), 2013 (ACl, 2014)

handling charges, $24 \mathrm{~h}$ operation, geographical proximity to major markets and, over time, the reputation of the facility and the agglomeration of cargo brokers, forwarders and specialist handling agents.

Although the terms 'air freight' and 'air cargo' are often used interchangeably, air cargo actually describes two distinct types of operation: air freight and air mail. These categories can be further subdivided into general freight and mail, express freight and mail, outsize or specialist freight and humanitarian freight depending on the nature of the consignment and the speed with which it needs to be delivered.

Air cargo can either be transported in the holds of scheduled passenger flights (so-called 'bellyhold' cargo) or as 'pure freight' on dedicated cargo-only aircraft that have been specially constructed or converted for this purpose. Many of the world's major passenger airlines, including British Airways, Emirates and Lufthansa, operate dedicated cargo aircraft in addition to their passenger fleets, while cargo integrators such as FedEx, UPS and DHL specialise in transporting pure freight in cargo-only aircraft.

Interestingly, despite the global socio-economic importance of, and society's reliance on, air cargo (as demonstrated by the disruption to global supply chains caused by airspace closures as a result of the 2010 eruption of Iceland's Eyjafallajökull volcano (Budd et al., 2011)), it remains an area of transport activity that is relatively under researched. In recognition of air cargo's importance both to the health of national and regional economies and the commercial viability of airports, this paper provides an overview of the scale and scope of contemporary air cargo operations in the UK and a detailed case study of East Midlands airport (hereafter EMA).

The aim of the paper is to explore the historical planning decisions and contemporary management strategies that have enabled EMA to develop and retain two successful distinct yet complementary sectors that have resulted in it being both a busy passenger airport during the day and the UK's largest pure freight hub at night. Drawing on publicly available data on cargo throughput from the Civil Aviation Authority (CAA) and EMA, together with information supplied by personal communication 
with members of EMA's senior management team, the paper focuses on how the development of strategically important landside and airside infrastructure combined with a sustained policy of promoting air cargo as a sector equal in importance to passenger traffic has attracted new cargo operators to the airport and enabled EMA to obtain (and subsequently) retain its position as 'the UK's number one pure cargo airport' (EMA, 2013). The paper concludes by examining the extent to which EMA could serve as a model for other regional airports worldwide that are seeking to develop complementary passenger and cargo services.

\section{Flying freight: Air cargo operations in the UK}

UK airports handled $2539813 \mathrm{t}$ of freight and mail in 2012 (CAA, 2013). This figure comprised $2307341 \mathrm{t}$ of freight $(90 \cdot 8 \%$ of the total) and $232471 \mathrm{t}$ of mail (9.2\% of the total) (data derived from CAA (2013)). Air cargo accounts for approximately $25 \%$ (by value) of the UK's total international trade and directly supports 39000 UK jobs (FTA, 2008; SDG, 2010). In 2008, £95 billion of goods were transported by air between the UK and nonEU countries (representing $35 \%$ of the UK's extra-EU trade) of which industrial machinery, electronic equipment and motors, and jewellery materials accounted for $£ 21 \cdot 3$ billion, $£ 14 \cdot 2$ billion and $£ 14$ billion, respectively (SDG, 2010).

General air freight and mail occupies the biggest market share by volume, accounting for $65 \%$ of the UK total in 2008 (SDG, 2010). Around two thirds of this is transported as bellyhold cargo (FTA, 2008). Express freight represents the second biggest market, accounting for $430000 \mathrm{t}$ (or $18 \%$ ) of total 2008 volumes (SDG, 2010). Unlike general cargo, $62 \%$ of express freight is flown by air cargo integrators and these flights account for around $4 \%$ of all commercial air traffic movements in the UK (FTA, 2008). Specialist cargo and specialist mail, respectively, accounted for the remaining 10\% (245000 t) and 7\% (169000 t) of the UK total (SDG, 2010).

Although 45 UK airports handled freight or mail in 2012, the majority of cargo traffic was concentrated at a few airports, mainly in London and the south east (see Table 2). London Heathrow alone handled $61 \cdot 3 \%$ of the UK total (CAA, 2013)

\begin{tabular}{lrc}
\hline Airport & $\begin{array}{c}\text { Total } \\
\text { freight: } t\end{array}$ & $\begin{array}{c}\text { Change on } \\
\text { 2012: \% }\end{array}$ \\
\hline London Heathrow (LHR) & 1422939 & -3 \\
East Midlands airport (EMA) & 266968 & 1 \\
London Stansted (STN) & 211952 & -1 \\
London Gatwick (LGW) & 96724 & - \\
Manchester (MAN) & 96373 & -1
\end{tabular}

Table 2. Top five UK airports for air freight, 2013; data derived from CAA (2014) while the four principal London airports - Heathrow, Gatwick, Stansted and Luton - handled $75.9 \%$ of the UK's air cargo by volume in 2012 (CAA, 2013). Nationally, 90.5\% of the volume of all the country's air freight and air mail in 2012 was handled by five airports, while the top ten cargo facilities handled $96.7 \%$ of the national total.

Yet, despite the dominance of airports in London and the south east, CAA figures show that a number of regional airports also support significant air cargo operations. Two of the UK's top five cargo airports, East Midlands and Manchester, are located over $185 \mathrm{~km}$ and $300 \mathrm{~km}$ northwest of London, respectively. Of these two facilities, EMA currently handles $11.8 \%$ of the UK total, making it second only in importance to Heathrow.

Unlike Heathrow, Gatwick and Manchester, virtually all air cargo (by volume) at East Midlands and Stansted is transported as pure freight on dedicated cargo aircraft. This traffic split introduces a number of interesting business management and operational implications for all five airports and reveals a great deal about their respective business models and operating niches. The implications of this for EMA are discussed in subsequent sections.

Whereas Heathrow and Gatwick (and, to a lesser extent, Manchester) are relatively capacity and slot constrained and have strict operating conditions that prevent full $24 \mathrm{~h}$ flight operations, East Midlands and Stansted currently have spare capacity and EMA has an unrestricted $24 \mathrm{~h}$ operating licence. This allows EMA to serve passenger aircraft during the day and freight aircraft at night. On the other hand, Heathrow and Gatwick, owing to the absence of slots and more restricted hours of operation, see virtually all of their air cargo arrive in the holds of scheduled passenger services. In addition, East Midlands and Stansted offer further advantages for cargo operators. Both are located in more rural areas of the country where land is cheaper and relatively fewer people are affected by aircraft noise; both are surrounded by greenfield sites that could be made available for future expansion (subject to planning permission); both are located near major trunk roads for ease of delivery and onward distribution; and both are now owned and operated by the same company Manchester Airports Group (MAG). EMA has the added advantage of being centrally located within the UK near the intersection of major north-south and east-west trunk roads.

The history of how EMA, a former World War II military airfield, has developed into the UK's largest pure cargo facility offers valuable insights for other regional airports both within Europe and worldwide that are seeking to develop complementary passenger services during the day and cargo operations at night. The following section describes the historical development of EMA and draws on the insights of senior managers at the airport to identify the key strategic planning interventions and infrastructure development projects that have enabled EMA to develop its unique operating niche. 
Transport

Volume 168 Issue TR2
Developing air cargo operations at

regional airports

Budd, Ison and Budd

\section{Developing air cargo services at regional airports: A case study of EMA}

The origins of aviation at EMA can be traced back to 1916 when Castle Donington airfield was established to serve the needs of 38 Squadron in their defence of Midlands' airspace during World War I. Abandoned after declaration of the armistice, the site was subsequently redeveloped as a military airfield with a hardsurfaced runway during the World War II before being closed for a second time in 1946. In late 1947, the site was acquired by the UK Ministry of Civil Aviation as part of a new national airport plan that sought to concentrate passenger services at a few key airports (Sealy, 1976). By the mid-1950s it was apparent that the existing municipal airport serving the East Midlands at Burnaston near Derby was becoming obsolete as the grass runways could not support the weight of the new post-war commercial aircraft that were being introduced.

The need for a replacement facility was first articulated by the Corporation of Nottingham which, together with a consortium of local authorities, formed a Joint Airport Committee (JAC). After evaluating a number of potential sites, the JAC decided that the abandoned airfield at Castle Donington should be developed as Burnaston's successor (Walker, 2005). It was thought that the site offered significant development potential as it lay roughly equidistant between the region's three major cities of Leicester, Derby and Nottingham, boasted favourable flying conditions and, most importantly, was adjacent to the proposed London-Leeds M1 motorway, the first section of which opened in November 1959. From its inception, the new facility was promoted as a 'motorway airport' with the supporting local authorities demonstrating an early appreciation of the future strategic importance of fast, easy and efficient road access to the airport's commercial future (Rowley, 1965). The initial planning application was submitted in 1960, construction commenced in spring 1964 and the new EMA opened for commercial civilian operations on 1 April 1965.

In its first 12 months of operation, EMA handled 118300 passengers and $545000 \mathrm{~kg}$ of air freight (EMEPC, 1966). These figures were considered to vindicate the JAC's choice of site and the airport stated its ambition to become the 'Clapham Junction' of the air for UK air freight (Wraith, 1966: p. 279). Much of EMA's early cargo traffic comprised fresh agricultural produce from the Channel Islands but, as the airport grew, new high-value and perishable commodities including manufacturing parts for the nearby vehicle manufacturing sites and aerospace factories in Derby began to be handled. By 1968, EMA was processing over $2500 \mathrm{t}$ of air freight a year (Metcalfe, 1970). In order to have the infrastructure necessary to accommodate future development, the airport invested in a continuous programme of airside infrastructure developments and new air traffic control technologies during the late 1960s and early 1970s. These included a runway extension in 1969, the installation of an instrument landing system in 1970 and the provision of controlled airspace in 1971. These developments collectively enabled the airport to handle the larger commercial aircraft that were being progressively introduced into airline service during the 1970 s as well as enabling aircraft to safely use the airport $24 \mathrm{~h}$ a day in all but the worst of weather conditions (Budd, 2007; Walker, 2005). Given its central location, good road links and the airport's emphasis on ensuring the delivery of efficient customs checks, the airport claimed that 'goods for export can leave EMA after 8pm and be in Brussels or Copenhagen in the early hours of the following morning' (Anon, 1965: p. 19). Such speed reportedly 'impressed customers everywhere' and helped attract additional cargo services to the airport (Metcalfe, 1970).

Between 1970 and 1979, cargo throughput increased to $6283 \mathrm{t}$ and passenger numbers were boosted by the arrival and increased popularity of inclusive tour charter services (Walker, 2005). By the early 1980s, EMA was reporting year-on-year double-digit cargo growth and by 1985 it was the fourth busiest cargo airport in the country, handling $27779 \mathrm{t}$ (Walker, 2005). In 1987, the airport was identified as being a suitable candidate for privatisation and in 1993 it was bought by the National Express Group for $£ 24.3$ million (EMIA, 1993). In 1994, EMA succeeded in attracting major US cargo integrator UPS to join DHL (which had been at the airport since 1989) and centralise its UK operations at EMA on account of EMA's location, potential for expansion and unrestricted $24 \mathrm{~h}$ operation (EMA, 1994). However, the growth in cargo flights during the decade, particularly those that operated at night and which were predominately flown by older and noisier aircraft, created growing tension in some sections of the local community who objected to the noise created by the low-flying aircraft.

By 2005, the situation was becoming acute. Over 60 aircraft (representing just under a third of the daily traffic total) were operating every night between the hours of 23:30 and 06:00 local time - more than that at any other UK airport (Budd, 2007) - and local protest groups formed to oppose the acoustic intrusion these services created (Budd, 2009). In response, EMA introduced a number of noise-monitoring and mitigation measures and encouraged (where possible) cargo operators to remove the oldest and nosiest aircraft from their fleet by introducing financial incentives to operate quieter aircraft. The noise reduction and mitigation measures include (Budd et al., 2013; MAG, 2013)

noise preferential routes for departing aircraft

an automated noise and track monitoring system

an online web-track facility to enable residents to identify noisy flights

- the introduction of less acoustically intrusive continuousdescent arrivals

- different landing charges for day and night-time operations

restrictions on training flights and overflying local villages

- subsidised noise insulation for local residents

a system of penalty charges for operators who breach strict noise criteria (the proceeds from which are used to support local community projects). 
By 1995, EMA had become the UK's largest pure cargo airport by volume, and freedom from public sector borrowing restrictions allowed the airport to use private capital to fund the construction of a new 25 ha business park on land adjacent to the eastern cargo apron in March 1999. The development of the landside Pegasus business park enabled companies including Holiday Inn Express, Radisson Blu, Heavyweight Air Express and Price Waterhouse Coopers to establish a presence at the airport.

Other infrastructure developments at this time included a new $£ 3.5$ million air traffic control tower (which became operational in April 1999) and a new dedicated cargo facility at the western edge of the airport (Cargo West). Both had a major influence on the continued development of EMA.

Unlike air traffic control services at most other major UK airports, EMA's air traffic controllers are directly employed by the airport operator. This allows for closer synergies between the two areas of the business and has undoubtedly contributed to the airport's growth. The joint development of Cargo West by EMA and cargo integrator DHL, meanwhile, represented another key intervention in ensuring the continued expansion of EMA's cargo capacity. The multi million pound complex opened in 2000 and comprises a $32516 \mathrm{~m}^{2}$ semi-automated sorting facility, a $8361 \mathrm{~m}^{2}$ three-storey office block and a $11148 \mathrm{~m}^{2}$ cargo loading area. The adjoining $160000 \mathrm{~m}^{2}$ western cargo apron has 18 stands able to accommodate aircraft as large as the B747 and An-124. The landside loading area has 35 docks for heavy goods vehicles and a further 35 remote spaces that offer fast and easy road access to the M1, A50 and M/A42 for onward distribution (EMA, 2013). The new western cargo facilities complemented the existing $60000 \mathrm{~m}^{2}$ eastern cargo apron, which serves UPS and TNT, and which features 12 aircraft stands that can accommodate An-124, B747, B767 and B737 aircraft (EMA, 2013). Four of the airport's five cargo terminals (terminals 2, 3, 4 and 5) are located immediately adjacent to this eastern cargo apron and they collectively offer over $20903 \mathrm{~m}^{2}$ of airside warehousing and office accommodation. The impact of these new and expanded facilities on cargo throughput at EMA has been significant. The landside Cargo Village near the eastern apron provides a further $13006 \mathrm{~m}^{2}$ of office and warehousing space.

Despite the recent construction, further development potential still exists. The airport's commercial property portfolio currently extends to almost 89 ha. EMA's property team manages $17094 \mathrm{~m}^{2}$ of cargo accommodation, which ranges in size from $76.6 \mathrm{~m}^{2}$ units to $6310 \mathrm{~m}^{2}$ transit sheds, and the airport also owns large areas of undeveloped land (EMA, 2013).

In March 2001, National Express sold both EMA and Bournemouth airport to Manchester Airports Group (MAG) for $£ 241$ million. Under MAG’s ownership, further investments were made to support the growth of cargo services. In December 2003, the UK government's white paper on the future of air transport recognised the national importance of developing passenger and freight services at EMA and predicted that the airport could be handling over 12 million passengers and $2.5 \mathrm{Mt}$ of cargo on 60000 cargo flights a year by 2030 (DfT, 2003). In anticipation of future growth, EMA submitted an airspace change proposal to the CAA to reorganise how air traffic movements were handled to improve capacity and safety. Following a number of amendments, the airspace change was approved and became effective in May 2005 (Budd, 2007).

Although neither passenger nor cargo volumes have increased as fast as anticipated by the DfT (2003) or the airport's 2006 master plan (EMA, 2006), cargo throughput at EMA has increased dramatically since 1965. Major growth occurred in 1993-1994 following the airport's privatisation and the subsequent arrival of UPS, and then again after the Cargo West facility opened in 2000 and EMA become DHL's main hub for the UK and Ireland with 20 cargo aircraft based on site. Although the 2008-2009 global economic downturn resulted in a temporary softening of demand for air freight, demand for air mail showed more resilience and the airport was not adversely affected by the immediate softening of air travel demand that occurred after the 9/11 terrorist attacks.

Today, EMA is the thirteenth busiest passenger airport and the largest pure freight airport in the UK, handling $37.4 \%$ of all the UK's pure freight and $28.7 \%$ of the UK's pure mail (CAA, 2012). By volume, it is the fifteenth largest cargo airport in Europe and the 65th largest in the world (EMA, 2013). Both scheduled, regular charter and ad hoc cargo flights operate to a wide range of destinations within the UK as well as to Europe, the Far East and the USA. Although information on the exact origin/destination of imports and exports is not collected, EMA's main import/ export countries are Belgium (by way of TNT's hub), Germany (by way of UPS and DHL), the UK (courtesy of the Royal Mail) and the USA (via DHL and UPS).

The airport's single $2893 \mathrm{~m} \times 60 \mathrm{~m}$ east-west grooved flexible asphalt runway has an International Civil Aviation Organisation (ICAO) pavement classification number $(\mathrm{PCN})$ of $78 / \mathrm{F} / \mathrm{C} / \mathrm{W} / \mathrm{T}$. This means the runway's load-bearing capacity is sufficient to safely support operations by all major commercial aircraft up to and including the An-124, B747-400F and Antonov 225 (MAG, 2013) (Table 3).

In addition, the airport's $23 \mathrm{~m}$ wide asphalt taxiways and $350000 \mathrm{~m}^{2}$ of brushed concrete aircraft aprons and ramp areas (which feature 30 dedicated cargo stands) are all certified to PCN63, meaning that they can safely support the weight of heavy cargo aircraft. This allows cargo airlines including Aerologic (B777F), DHL (A300, B757F, B767F), Europe Airpost (B737), Icelandair Cargo (B757F), Jet2 (B737, B757), TNT (A300, B737) and UPS (B767F) to operate a range of aircraft into EMA and ensures the airport can accommodate ad hoc cargo charters and humanitarian relief flights that are flown using a range of different aircraft. 


\begin{tabular}{lclllll}
\hline $\begin{array}{l}\text { Runway } \\
\text { designation }\end{array}$ & $\begin{array}{c}\text { Threshold } \\
\text { elevation: } m\end{array}$ & ILS & \multicolumn{1}{c}{ TORA: $m$ TODA: $m$ ASDA: $m$ LDA: $m$} \\
\hline 27 & 93 & CAT IIIb & 2893 & 3204 & 2923 & 2713 \\
09 & 86 & CAT I & 2893 & 3352 & 2923 & 2763
\end{tabular}

Table 3. EMA technical data (EMA, 2013): ILS, instrument landing system; TORA, take-off runway available; TODA, take off-distance available; ASDA, actual surface distance available; LDA, landing distance available

The airport's unrestricted $24 \mathrm{~h}$ operating licence, 24/7/365 provision of customs, immigration and border inspection posts for the clearance of animal products and lack of slot restrictions mean that cargo operators can fly at any time of the day or night. Furthermore, the provision of a CAT IIIb all-weather instrument landing system on runway 27 combined with favourable flying conditions at the site means that flights are rarely disrupted by adverse weather and the airport often handles weather diverts from other UK airports. The expansion of EMA's controlled airspace and the reorganisation of flightpaths in May 2005 further improved the safety and efficiency of air traffic services (Budd, 2007). The provision of specialist ground handling and 'build and break' cargo services by some of the world's leading ground service agents enable cargo integrators to both consolidate and separate cargo shipments at EMA. Owing to investments in airside infrastructure and handling equipment, EMA is also licenced to handle dangerous goods, radioactive materials and outsized and specialist cargo, including regular shipments of aircraft engines.

In September 2013, EMA handled 2138 cargo movements (an average of over 71 flights per day or approximately 500 per week) to/from destinations as diverse as Brussels, Leipzig and Cincinnati (personal communication, Bill Blanchard, Cargo Portfolio Manager, EMA, 2013). In order to support the continued future vitality of the cargo sector, the management team at EMA has introduced a number of policies and initiatives designed to support cargo operators. The airport convenes a dedicated EMA Freight Liaison Group (FLG), which discusses areas of mutual interest and concern, and representatives of major cargo companies are invited to sit on the airport's Independent Consultative Committee (ICC), which brings together local parish councillors, members of environmental and local community groups and other interested stakeholders. Feedback obtained from both the FLG and ICC helps EMA to identify potential challenges, prioritise capital investment in areas of strategic need and work with local community representatives to try and mitigate the impact of airport and cargo operations on local residents. In addition, strategic appointments at senior management level have ensured that the airport benefits from having staff with not only aeronautical expertise but also those with experience from the commercial and retail sectors which, given the growing impor- tance of non-aeronautical revenue streams to airports, is allimportant.

In terms of express freight services, the airport's master plan recognised them 'not only as an increasingly important economic sector in their own right' but, more importantly, as 'an essential contributor to the capabilities and competitiveness of other sectors of both the East Midlands and UK economy. It also provides the East Midlands with a unique opportunity among UK regions to capitalise on the investment and development potential arising from the industry, its supply chain and its customers' (EMA, 2006: p. 17).

The identification and adoption of a 'freight friendly' policy aims to provide a high level of service to all EMA's cargo customers and clients. Significantly, this service extends not only to the cargo airlines that operate on site but also to the numerous cargo charter brokers, cargo handling agents, freight forwarders and major cargo shippers. According to Bill Blanchard, cargo portfolio manager for MAG at EMA, this policy is primarily achieved through "communication, discussion and working closely with the cargo aircraft handling agents at the airport to provide an efficient, seamless and hassle free experience'. The vital element that underpins EMA's success at developing complementary passenger and freight services is undoubtedly due to the fact that the two operations are treated with equal importance. In the words of the airport's cargo portfolio manager, 'What sets EMA apart from other airports is that we treat cargo operations as equals to our passenger operations'.

\section{Conclusion}

From its opening in April 1965 as a commercial facility, EMA has actively sought to encourage the development of air cargo through a series of strategic planning and management interventions. Successive public and private owners have recognised the need to develop a comprehensive yet complementary range of passenger services during the day and cargo operations at night. Thanks to its extensive airside infrastructure, unrestricted $24 \mathrm{~h}$ operations, 'in-house' air traffic control service and the policy of treating passenger and cargo operations as equal, EMA has been able to develop its operations to successfully support two very important, yet very different, sections of the global air transport 
system. In doing so, EMA has demonstrated that, by spatially and temporally segregating passenger and cargo flights, it is possible to develop a unique operating niche that not only reduces commercial vulnerability to downturns in any one sector but also maximises the revenue-generating potential of one of its most valuable assets, its runway.

This is not to claim, however, that there have not been challenges. Indeed, the unique temporal profile of air traffic movements at EMA means that at certain times of the year the airport is busiest in the early hours of the morning. This has created a degree of community tension, with some local residents vociferously complaining about the noise of night flights. In response, the airport operator has instigated a range of measures, including fining aircraft operators when their aircraft deviate from prescribed flightpaths or exceed noise thresholds, and inviting community representatives to regularly meet and discuss their concerns with the airport through ICC meetings.

The development of successful cargo services at EMA offers a number of valuable lessons for regional airport operators worldwide that are seeking to expand cargo services.

The first of these is the importance of geographic location and good surface access links. EMA was deliberately chosen as the site of the new airport for the East Midlands region on account of its centrality and proximity to major trunk roads. This strategic planning decision, taken by the supporting local authorities in the early 1960 s, was instrumental in enabling the airport to become what it is today. Indeed, were it not for its location and access, it is questionable to what extent the airport would have been able to develop.

The second most important lesson relates to the provision of airside and landside infrastructure that is capable of handling not only the aircraft that are using a facility at the moment but also the aircraft that might potentially want to use the airport in the future. As this paper has shown, EMA has continually upgraded its runways, apron areas, air traffic control services and landside infrastructure to better accommodate existing demand and facilitate future growth. While traffic growth has not always materialised as forecast, the availability of spare capacity means EMA is an attractive proposition for both passenger and cargo operators.

Thirdly and finally, the case study of EMA has demonstrated the importance of having the right management team, possessing both professional aeronautical and commercial experience, and the right management ethos - one that seeks to continually identify new challenges, innovate its product, proactively engage with clients and customers at all stages of the air transport service delivery chain and continually reflect on its commercial and strategic performance. In a world of ever-increasing globalisation and the progressive dominance of 'super hub' airports, it is salient to note that opportunities remain for regional airports to carve out successful and distinct operating niches and compete on the world stage.

\section{Acknowledgements}

The authors thank Andy Cliffe, managing director of EMA, Bill Blanchard, key cargo account manager for MAG at EMA, and their colleagues at EMA for their help in the preparation of this paper.

\section{REFERENCES}

ACI (Airports Council International) (2014) Preliminary World Airport Traffic and Rankings, 2013. See http://www.aci.aero/ News/Releases/Most-Recent/2014/03/31/Preliminary-WorldAirport-Traffic-and-Rankings-2013-High-Growth-DubaiMoves-Up-to-7th-Busiest-Airport-on (accessed 01/09/2014).

ACI-NA (Airports Council International North America) (2012) Airports Council International Air Cargo Briefs Produced by the ACI Air Cargo Committee. See http://wwwassets. listpilot.net/acina/files/Air\%20Cargo\%20Issues(1).pdf (accessed 01/11/2012).

Anon (1965) East Midlands Airport Castle Donington. Industrial Nottingham, July, pp. 5-31.

ATAG (Air Transport Action Group) (2012) Aviation. Benefits Beyond borders. ATAG, Geneva, Switzerland.

Bowen J (2014) The economic geography of air transport. In The Geographies of Air Transport (Goetz A and Budd LCS (eds)). Ashgate, Farnham, UK, pp. 41-59.

Budd LCS (2007) Producing Airspace: The Contested Geographies of Nottingham East Midlands Airport. PhD thesis, Loughborough University, Loughborough, UK.

Budd LCS (2009) Air craft: Producing UK airspace. In Aeromobilities (Cwerner S, Kesselring S and Urry J (eds)). Routledge, Abingdon, UK, pp. 115-134.

Budd LCS, Griggs S, Howarth D and Ison S (2011) A fiasco of volcanic proportions? Eyjafjallajökull and the closure of European airspace. Mobilities 6(1): 31-40.

Budd LCS, Budd T and Jefferson A (2013) The importance of collaborative dialogue in the aircraft noise debate: examples of flightpath changes at UK airports. Journal of Airport Management 7(1): 71-87.

CAA (Civil Aviation Authority) (2012) Size of Reporting Airports 2012 Comparison with 2007. CAA, London, UK. See http://www.caa.co.uk/docs/80/airport_data/2012Annual/ Table_01_Size_of_UK_Airports_2012_Comp_2007.pdf (accessed 16/04/2013).

CAA (2013) UK Airport Statistics - 2012 Table 02 (2) Summary of Activity at UK airports. CAA, London, UK. See http://www.caa.co.uk/docs/80/airport_data/2012Annual/ Table_02_2_Summary_Of_Activity_at_UK_Airports_ 2012.pdf (accessed 10/10/2013).

CAA (2014) UK Airport Statistics - 2013. Table 13.2 Freight 2003-2013. CAA, London, UK. See http://www.caa.co.uk/ docs/80/airport_data/2013Annual/Table_13_2_Freight_ 2003_2013.pdf (accessed 12/12/2014).

DfT (Department for Transport) (2003) The Future of Air Transport. HMSO, London, UK.

EMA (East Midlands Airport) (1994) East Midlands Airport Annual Report, 1994. EMA, Castle Donington, UK. 
Developing air cargo operations at

regional airports

Budd, Ison and Budd
EMA (2006) Master Plan 2006. EMA, Castle Donington, UK.

EMA (2013) Cargo Homepage. EMA, Castle Donington, UK. See http://www.emacargo.com (accessed 10/10/2013).

EMEPC (East Midlands Economic Planning Council) (1966) The East Midlands Study. HMSO, London, UK.

EMIA (East Midlands International Airport) (1993) East Midlands Airport Report and Annual Accounts, 1993. EMIA, Castle Donington, UK.

FTA (Freight Transport Association) (2008) Air Freight June. FTA, Tunbridge Wells, UK.

Gardiner J, Ison S and Humphreys I (2005a) Factors influencing cargo airlines' choice of airport: an international survey. Journal of Air Transport Management 11(6): 393-399.

Gardiner J, Humphreys I and Ison S (2005b) Freighter operators' choice of airport: a three-stage process. Transport Reviews 25(1): 85-102.

Graham A and Ison S (2014) The role of airports in air transport. In The Geographies of Air Transport (Goetz A and Budd LCS (eds)). Ashgate, Farnham, UK pp. 81-102.

Kasarda JD, Appold SJ and Mori M (2006) The Impact of the Air
Cargo Industry on the Global Economy. University of North Carolina, NC, USA. See https://www.tiaca.org/images/tiaca/ PDF/The \%20Impact $\% 20$ of $\% 20$ of $\% 20$ the $\% 20$ Air $\% 20$

Cargo\%20Industry\%20on\%20the\%20Global\%20Economy.pdf (accessed 10/10/2013)

MAG (Manchester Airports Group) (2013) Particulars of [EMA] Aerodrome Site May 2013. MAG, Manchester, UK.

Metcalfe A (1970) East Midlands Airport Official Handbook, 4th edn. Manor Publishing, Bradford, UK.

Rowley A (1965) East Midlands Airport Official Handbook, 1st edn. Manor Publishing, Bradford, UK.

SDG (Steer Davies Gleave) (2010) Air Freight. Economic and Environmental Drivers and Impacts Report - Final. SDG, London, UK.

Sealy K (1976) Airport Planning and Airport Strategy. Oxford University Press, Oxford, UK.

Walker B (2005) The Airport: Serving the East Midlands for 40 Years. Origination, Derby, UK.

Wraith RE (1966) The public inquiry into Stansted airport. The Political Quarterly 37(3): 265-280.

\section{WHAT DO YOU THINK?}

To discuss this paper, please email up to 500 words to the editor at journals@ice.org.uk. Your contribution will be forwarded to the author(s) for a reply and, if considered appropriate by the editorial panel, will be published as a discussion in a future issue of the journal.

Proceedings journals rely entirely on contributions sent in by civil engineering professionals, academics and students. Papers should be 2000-5000 words long (briefing papers should be 1000-2000 words long), with adequate illustrations and references. You can submit your paper online via www.icevirtuallibrary.com/content/journals, where you will also find detailed author guidelines. 